\title{
Through the Lens of a Millennial: Opening the Aperture of Millennials' Views of Leaders
}

\author{
Allison Sadler \\ Cadre Consultants \\ Julianna Grabianowski \\ Doane University \\ Greg Ashley \\ Bellevue University
}

\begin{abstract}
As more women joined the workforce in the last few decades, scholars have continued to research why women do not occupy more senior levels of leadership. While many variables have been researched, a pervasive theory is that women are expected to act in communal ways, but leadership is described as agentic; typically attributed to male behaviors. Namely, women in more senior roles must display male, agentic behaviors to be perceived as a credible leader, yet still maintain their communal traits to avoid being perceived as duplicitous. With more females in the workplace, acting as new exemplars for the millennial workforce, have the views of leadership changed to be less agentic?

This quantitative study investigated; whether male millennials in the workforce maintain as agentic a view of leadership as their predecessors, whether female millennials in the workforce maintain as agentic a view of leadership as their predecessors, and whether the presence of women in leadership roles has influenced leadership behaviors in either gender. In this study, millennials are surveyed regarding the most important leadership characteristics and how gender undulates through the perceived effectiveness. The researchers found that leadership descriptors are more gender-agnostic, influencing a broader view of how leadership is seen across both genders. The implications for this finding are that millennials are softening the more traditional view of agentic leadership and expanding leadership to include more communal traits.
\end{abstract}

Keywords: gender, leadership, millennials, generations, differences

\section{Introduction}

At the inception of gender leadership studies, researchers analyzed differences in the way genders evinced in various leadership styles (Schein, 1973). During the 1970s, when most leaders in the workforce were male, it is not surprising that most leadership characteristics were attributed to male, or agentic, behaviors (Warner, 2014). As more women joined the workforce 


\section{MILLENNIALS' VIEWS OF LEADERS}

and became leaders, the concept of role congruence became more focal for researchers. As women tried to exemplify leadership behaviors that were primarily agentic and leader-like, men and women experienced role incongruence (Schein, Mueller, Lituchy, \& Liu, 1996). Female leaders were presented with a dichotomy; exhibit natural, communal behaviors and not be seen as leader-like or adopt agentic behaviors and contrast societal expectations. Newer generations are in today's workforce, bringing modern values and subsequent needs for new ways of leading, suggesting that views of effective leadership may be changing (Anderson, Baur, Griffith and Buckley, 2017; Balda \& Mora, 2011). Decades of research have revealed that leadership effectiveness is present in both genders, but social roles preclude women from being seen and represented as leaders (Eagly and Karau, 1991). Will this next generation be able to embrace more communal ways of leading in society? Will millennials accept female leaders operating in an agentic manner?

As more females have entered the rungs of leadership, the millennial generation has a unique opportunity to observe women as leaders with a wider aperture, inclusive of both agentic and communal behaviors as defined leadership qualities. By some accounts, the perception of a leader is moving away from iconic, traditionally male-dominated exemplars to a broader definition of leadership as embracing the responsibilities of a role (Goldberg, 2017). Anderson et al. (2017) submit that millennial workers have different cognitions about leadership than Gen-

Xers or Baby Boomers. Balda \& Mora (2011) proffer that millennials desire inclusive leadership in less bureaucratic organizations, along with value congruence and accessible communication. These new attitudes are ripe for examining the past and current view of effective leadership. To understand how leadership may be redefined, we first explore traditional definitions of leadership, gender in leadership, and define the generations.

\section{Leadership Perspectives}

Leadership theories are a cacophony of behaviors, traits, relationships, structures, and processes that are ensconced in individuals and their exchanges in an effort to influence work (Kilburg \& Donohue, 2011). One's leadership style is the combination of the leader's personal traits and behaviors and impacts of that style on followers in ways that build organizational commitment, coordinate work, and expand networks to advance organizational goals (Day, Zaccaro, \& Klimoski, 2001). While extant theories of leadership are grounded in individual leader attributes (behaviors, traits, personal influence, etc.), more recent theories expand leadership in a more dynamic state based on situations (Vroom \& Jago, 2007).

In more nascent theories, the definition of leadership is augmented to include interactions with others, relationships with followers, and the effects of leadership on culture (Garrick, 2006). Ciulla (as cited in Harvey and Riggio, 2011) offers the following expansive definition:

A one-size-fits-all definition of leadership is not possible because the properties of normative terms are referentially opaque. Hence, it makes more sense for leadership scholars to focus on revealing the moral, social and psychological properties of leader than on trying to come up with the ultimate definition of a leader (p. 62). 
Crossan and Olivera (2006) exemplify this expansive definition of leadership in their article on cross-enterprise leadership which highlights the disappearing boundaries of leadership scope and responsibility. While emerging proposals call for leadership as an ever-evolving process, other theories build work to solidify original definitions with more modern contexts.

In addition to the already complex and ambiguous study of leadership, gender nuances bring a new lens to the amorphous process of leading. In Schein's original 1973 study, leadership and gender were well-defined. Men occupied most leadership roles and those in leadership positions were defined as male-agentic in their attributes. As the study of leadership grows, the field harkens back to the role gender-related attributes play in leadership style and effectiveness. Scholars have observed differences in specific styles and traits between the genders (Eagly \& Johnson, 1990; Mandell \& Pherwani, 2003). Some authors have turned to how these differences influence effective leadership behaviors and how leaders cultivate followership in organizations (Rosener, 1990). In this study, millennials are surveyed regarding the most important leadership characteristics and how gender undulates through the perceived effectiveness.

\section{Gender Differences}

Early leadership research studied differences in characteristics between genders. Characteristics were studied to understand the relationship between managerial success and the aforementioned agentic and communal attributes. These characteristics were associated with a feminine or masculine label. Male traits were predominantly ascribed as requisites to managerial success and birthed the think manager-think male phenomenon (Schein, 1973). The gender differences have consistently been reinforced by research that attributes agentic (aggressive, ambitious, and dominant) characteristics to men and communal (cooperative, collaborative, and helpful) characteristics to women (Eagly \& Carli, 2007). These beliefs have impacted hiring, promotion, and placement decisions that disadvantage women who have not identified themselves with leader-like attributes or identified leaders with communal attributes (Schein, 1973).

Schein (1975) further studied how female managers ascribe characteristics to successful managers and stereotype female managers. From Schein's (1973) earlier work, female managers reinforced the earlier beliefs that masculine personality characteristics determine managerial success (1975). Furthermore, these beliefs were not bound to culture. Across multiple countries, men were found to endorse the think manager-think male phenomenon (Schein, Mueller, Lituchy, \& Liu, 1996).

As research evolved, scholars focused on gender differences in leadership styles. Women were observed demonstrating democratic styles while men employed autocratic styles (Eagly \& Johnson, 1990). Gender differences in task and interpersonal orientation manifested in laboratory settings, but were not observed in organizational settings (Eagly \& Johnson, 1990). Eagly and Johnson (1990) posited that gender differences in task and interpersonal orientation became less pronounced in organizational settings as leaders integrated more dynamic approaches based on relationships and situations that manifested in the organization. 
Eagly and Karau (1991) also found that both genders were equally as effective as leaders and possessed parallel talents. The research uncovered that while men are more likely to emerge as leaders, both genders have the capacity to be viewed as effective (Eagly \& Karau, 1991; Lanaj $\&$ Hollenbeck, 2015). Beyond gender, the leader's role or industry also plays a part in how the leader's effectiveness is perceived. For example, if the leader's role possesses more masculine attributes like decisiveness in financial industry decisions, then male leaders were viewed as more effective (Eagly \& Karau, 1991). Conversely, women fared better when the role required more feminine attributes like healthcare or education, bringing the issue full circle to the congruence of men and women leaders to their ascribed social roles (Eagly \& Johnson, 1990). When female leaders are in leadership roles that require communal behaviors, women are perceived as acting in alignment with the social role attributed them.

Millennials are the first generation to see women represented as senior leaders in organizations. Millennials are also seeing men take on more communal responsibilities like assistants, and seeing as their female counterparts ascend to senior positions in organizations. The obfuscation of social roles is assumed by millennials, but other generational differences have manifested and are changing the landscape of organizational behaviors and leadership theory.

\section{Defining the Generations}

Hundreds of millennial studies have lined the journals, describing the unique attributes of the generation. Strauss and Howe (2000) defined millennials as the cohort born between 1980 and 1999. A "new generation" is defined by specific attributes and values that have morphed from a prior group of peers.

\section{GenMe}

The public at-large has often coined millennials, "GenMe" (Twenge, 2010). The phrase refers to the egocentric nature of millennials that is often attributed to the overindulgent care and attention from the parents of millennial children (Cole, Smith, \& Lucas, 2002). The referent implications of this parental trend is that millennials desire the attention-seeking relationships in the workforce as adults. As a result, millennials are perceived as "high maintenance", constantly seeking guidance and direction from their leaders (Tulgan, 2009).

Millennials have also shown more focus on individualistic values like leisure time, flexible working arrangements, and self-assurance (Twenge, 2010). The self-absorbed perception is exacerbated by selfie-posts and constant updates on social media on one's status. The workplace result is that millennials view personal time and personal causes over their employment as a central part of their identity (Twenge \& Kasser, 2013). As a result, leaders must focus on providing meaningful work, reinforcement, and extrinsic motivation to the new generation in the workforce (Barzilai-Nahon \& Mason, 2010).

\section{Gen meaningful}

In stark contrast to the "GenMe" moniker, millennials are focused on contributing to an organization's goals and being socially responsible ( $\mathrm{Ng}$, Schweitzer \& Lyons, 2010). They desire work that allows them to add value both in and out of the workplace. The roots of this 
desire date back to school where community service was about "service learning" (Howe \& Strauss, 2000). The integration of learning through volunteering elevated the awareness of social responsibility and morality outside of the classroom.

With this focus on service and social responsibility, organizations must create a culture and environment that engenders these values. Organizations must develop leaders who will foster volunteerism outside of work, while finding meaningful assignments during the day (Great Expectations, 2016).

\section{Technology \& collaboration}

The millennial generation has experienced unprecedented change and access to technology. As a result, millennials can quickly connect and collaborate in gaming pursuits and social media. Networks can span contents and communication is profoundly digitized in nonverbal forms (Hershatter \& Epstein, June 2010). Millennials have shifted the paradigm of making individuals work in a team to finding a team of disparate talents that work (Curtis, 2010).

Consequently, technology has enabled millennials to see a less-hierarchical world, and one that is collaborative (Espinoza, Ukleja, \& Rusch, 2010). The millennial view of teams and flattened constructs translates into organizations where millennials expect to interact with all levels of the organization, not just their defined teams. In kind, leaders need to encourage teaming across the horizontal boundaries and find ways to provide open access to people and information (Anderson, Baur, Griffith, \& Buckley, 2017; Curtis, 2010).

\section{Significance of Study}

While decades of research have covered differences in leadership styles between genders, nascent studies have failed to elucidate the nuances in millennials' perceptions of leadership. Thus, our study advances prior research by exposing these insipid differences and how they apply in the modern workplace. This research addressed the following questions:

\section{Research Questions}

- Do male millennials in the workforce maintain as agentic a view of leadership as their precedents?

- Do female millennials in the workforce maintain as agentic a view of leadership as their precedents?

- Has the presence of women in leadership roles influenced a broader range of leadership attributes that encompass both communal and agentic behaviors?

\section{Research Design}

Using a quantitative approach, this study started with the collection and analysis of quantitative data. The research produced context for how views of leadership have changed with the entrance of the millennial workforce 
Thus, the propositions for the quantitative study were:

Proposition 1. It is proposed at least two communal behaviors will be chosen as leadership descriptors.

Proposition 2. It is proposed fewer agentic behaviors will be chosen as leadership descriptors.

\section{Method}

\section{Procedure \& Data Collection}

The purpose of this study was to understand how millennials view leadership after having both male and female leader exemplars in the workforce during their generation. The researchers were further intending to uncover if the millennial generation views leadership any differently than the original studies (Schein, 1973) conducted. Therefore, the study asked males and females born between the years 1980 - 1995 to complete the Schein Descriptive Index (Schein, 1973) in survey form online. An additional context was added to the online survey to understand if there were any significant variances by industry. Participants were asked to selfreport the industry of their employer.

Prior to data collection, the approval of the Bellevue University Internal Review Board was sought. The survey was submitted online and participants were solicited electronically via social media tools (such as LinkedIn and Facebook) as well as emails. The study specifically targeted millennials (males and females born between the years 1980 -1995) and asked participants to complete the survey online. As mentioned, the primary contact was electronic and limited to the networks of the researchers and their network base; however, face-to-face solicitation promoted the research as well.

\section{Assessment and Measures}

The researchers used the Schein Descriptive Index (Schein, 1973), which consists of 92 items (suggested leadership characteristics) that participants were able to rate on a 5-point Likert scale from 5 (characteristic) to 1 (not characteristic). General demographical information of the participants was asked for as well (i.e. gender) and employer's industry. The survey could be completed at the subjects' convenience and participants were able to withdraw at any time or refuse to answer any questions they did not want to answer.

The measures included the 92 Schein Descriptive Index items that were previously studied and correlated with leadership characteristics (Schein, 1973). The dependent variables evaluated were used from the original study and analyzed to determine if there were any changes in how millennials attributed a male or female characteristic to a leadership characteristic. 
MILLENNIALS’ VIEWS OF LEADERS

Table 1

Variables in Original Study by Gender

\begin{tabular}{|l|l|}
\hline Variables Associated with Females & Variables Associated with Males \\
\hline Gentle & Leader-like \\
Caring & Responsible \\
Nurturing & Stable \\
Sensitive & Decisive \\
Friendly & Aggressive \\
Empathetic & Well-Informed \\
Helpful & Direct \\
\hline
\end{tabular}

\section{Sample}

The original study was targeted to several hundred individuals. Ninety individuals completed the study; however, only thirty-nine individuals completed the full survey. Researchers suspect that the global network of individuals participating precluded participants, with English as a second language, from understanding the descriptors. As a result, the sample size was significantly smaller than anticipated.

Twenty-two female and seventeen males completed the survey in full. Given that the sample of millennials were desired to be in the workforce, industry demographics were captured. Finance and Insurance represented $51 \%$ of the participants' industries. Education, government, and marketing were represented in small numbers.

\section{Validity and Reliability}

\section{Validity}

In order to establish solid construct validity, a researcher has to clarify the constructs s/he intends to study and identify the appropriate tools to operationalize these. A study should therefore define the construct(s) and identify appropriate operational measures. The present study meets the requirements mentioned as it clarifies constructs based on the intent of the study and utilizes appropriate measures.

\section{Reliability}

In order to establish reliability, it is important that all steps conducted in a study can be duplicated and result in similar findings. To maximize reliability, we did not modify the original questionnaire and simply replicated the instrument in an electronic version (Schein, 1973). This step actually can be interpreted as a strengthening of validity as it enabled a large sample size and geographical width. Parry (1998) reinforces that repeating a study will contribute to reliability; however, cases will naturally differ. 


\section{Data analysis}

The original study by Virginia Schein evaluated interclass correlations between how males and females described themselves, and subsequently how they described leaders to compare the two groups of responses (1973). In this study, the male and female self-ratings were excluded from the study and the respondents simply rated the descriptors of leadership on the Schein Descriptive Index using a 5-point Likert scale.

The analysis was conducted using mean ratings for each descriptor. Each of the ninetytwo descriptors was averaged and sorted from highest to lowest and analyzed by gender. These descriptors were then compared to the original Schein study and compared for differences.

\section{Findings}

Comparing the original study and the more recent results, some interesting findings emerged. The top-rated descriptor was "competent" with a mean score of 198. Competence was not listed in the original study, but emerged as the most highly rated descriptor for successful leadership. Closely linked, was "intelligent", which was also not represented in the original study, but both emerged as important descriptors for successful leaders. Finally "persistent" emerged as a descriptor that was not highlighted in the 1973 research. These findings are represented in Table 1 below.

Original descriptors that appeared in both studies include "leadership ability", "wellinformed", "self-confident", and "helpful". All of the descriptors were correlated with male responses with the exception of "helpful" which was associated with females.

\section{Table 2}

\section{List of Top Ten Rated Descriptors}

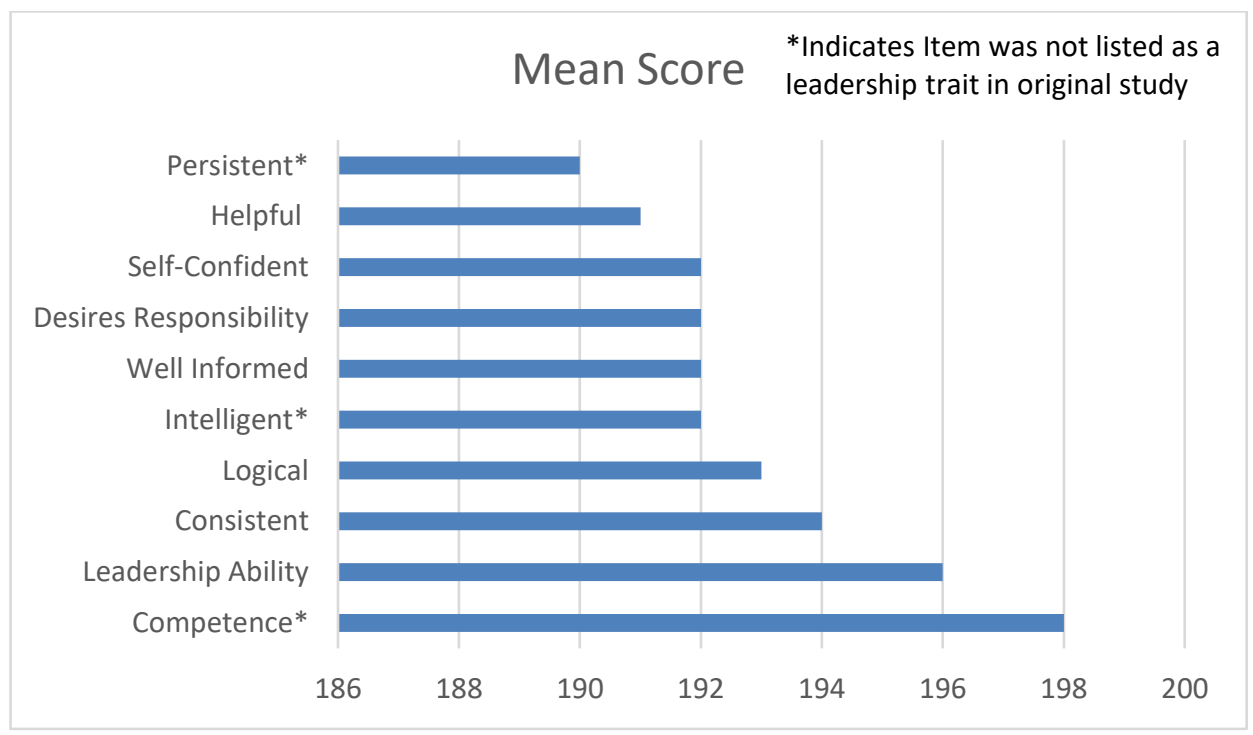




\section{Potential Bias}

While a researcher's approach should always be as neutral as possible to not bias the study's findings, it is almost an impossible task, as exactly those findings rely on the relationship between the researchers and the participants. The participants need to have the feeling they can trust the researchers, that s/he has an interest in what they are saying, and/or that there will be no consequences as a result of participating in the study. We are confident that the relationships/connections we used to solicit participants (email, Facebook, and LinkedIn) fulfilled the necessary conditions that were needed to gain trust (knowing the researcher(s) or knowing the person who shares the opportunity), and contributed to honest and relevant information, which, according to Parry (1998), in return adds to the study's validity.

\section{Limitations and Delimitations}

Several limitations apply to this quantitative study, which is based on data set of $n=39$ Whereas the most current study targeted participants born between 1980 - 1995 (translating into ages 23- 38 in the year 2018), the original data set of the Schein (1973) study had a slightly different age range in the bracket that is comparable. The original data set had a target $n=300$, with $n=113$ ages $24-39$ (1973).

A second limitation pertained to the length of the survey. With ninety-two suggested leadership characteristics that participants were able to rate on a 5-point Likert scale, some participants may have experienced fatigue, which can lead to misrepresented answers of the subjects. As we did not limit the distribution of the questionnaire geographically, the length in regards to quantity of foreign vocabulary could have contributed to fatigue and misinterpretation of the attributes, limiting the sample size.

Related to the second limitation, the sample size, and resulting power of the study, proved challenging. The statistical power of the study was .33 and requires a larger sample which will be explored in phase two of the research study.

\section{Implications}

Comparing the two studies elucidates some important themes. First, the original study was conducted when leadership exemplars were largely male. The 1973 study embodied the exemplars of leaders in the workforce at that time. In present day, more females are represented at the front and mid-level leadership levels than in 1973. As a result, this study reflected descriptors that were gender-agnostic than male-dominated as leadership descriptors. This implication poses an interesting question: Are the gender roles becoming more agnostic or are there more leaders in the workplace that demonstrate gender-agnostic leadership?

The recent study also highlights the need for traits that are more closely linked to the knowledge-era: "competent", "intelligent", and "persistent". These descriptors have been wellresearched as gender-neutral traits (Duckworth, 2016; Haier, 2004; Meisenberg, 2017). 
However, researchers have not studied how these traits impact leadership and their role in the social construct of gender.

\section{Future Research}

While the first phase of the research provided key insights, additional samples are necessary to bolster the statistical power. Future research should include additional participants, and perhaps a mixed-methods approach with qualitative interviews to complement the data. Mixed-method studies not only allow for the "what" but also the "why". A larger sample size, combined with interviews in a mixed-methods format, will bolster the understanding of the change. Providing the additional context for why millennials' views have changed could prove to be very valuable for organizations and scholars alike.

Future research should also include how gender roles in social context may underpin changes in gender roles in an organizational context, specifically in a leadership context. Do societal changes influence organizational roles or do the changes in organizational roles influence society? Researchers can benefit from understanding the changing landscape of gender in society in ways that benefit the future of organizational leaders.

It is clear that the descriptive rubric of a leader is evolving. Future studies may aim to predict how these competencies are changing and how gender roles will be impacted by these changes. Social and organizational roles will benefit from additional studies in the progressive changes of gender in leadership from the view of Gen $\mathrm{Z}$.

\section{References}

Anderson, H. J., Baur, J. E., Griffith, J.A., \& Buckley, R. M. (2017). What works for you may not work for (Gen)Me: Limitations of present leadership theories for the new generation. The Leadership Quarterly, 28, 245-260. http://dx.doi.org/10.1016/j.leaqua/2016.08.001

Balda-Bragan, J. \& Mora, F. (2011). Adapting leadership theory and practice for the networked, millennial generation, Journal of Leadership Studies, 5(3), 13-24. DOI:10.1002/jls.20229

Barzilai-Nahon, K., \& Mason, R. (2010). How executives perceive the net generation. Information, Communication \& Society, 13(3), 396-418.

Ciulla, J. (2011). Handmaiden and queen: What philosophers find in the question, "What is a leader?". In Michael Harvey \& Ronald E. Riggio. Leadership studies: The dialogue of disciplines (62). Massachusetts: Edward Elgar Publishing, Inc.

Cole, G., Smith, R., \& Lucas, L. (2002). The debut of generation y in the American workforce. Journal of Business Administration Online, 1(2).

Crossan, M. \& Olivera, F. (2006). Cross-Enterprise Leadership: A new approach for the $21^{\text {st }}$ century. Ivey Business Journal, 70(5), 1-6.

Curtis, G. (2010, September 3). Give your workplace a millennial makeover: Learning to think like your new generation of colleagues. Retrieved from https://www.cio.co.uk/itleadership/give-your-workplace-a-millennial-makeover-3430586/ 
Day, D.V., Zaccarro, S.J., \& Klimoski, R.J. (2001). Assessment of leadership outcomes. The nature of organizational leadership: Understanding the performance imperatives confronting today's leaders, 384-410.

Duckworth, A. (2016). Grit: The power of passion \& perseverance. New York, NY: Scribner Publishing.

Eagly, A.H. \& Johnson, B.T. (1990). Gender and leadership style: a meta analysis, Psychological Bulletin, 108(2), 233-256.

Eagly, A.H., and Carli, L.L. (2007), Women and the labyrinth of leadership. Harvard Business Review, 85(9), 63-71.

Eagly, A.H. and Karau, S.J. (1991), Gender and the emergence of leaders: A meta-analysis, Journal of Personality and Social Psychology, 60(5), 685-710.

Espinoza, C., Ukleja, M. \& Rusch, C. (2010). Managing millennials: Discover the core competencies for managing today's workforce. Hoboken, NJ: Wiley.

Garrick, L.E. (2006). 500 years of leadership theory: The challenge of learning to lead. Northshore Group. 15 pages. Retrieved from https://www.scribd.com/doc/15970829/500-Years-of-Leadership-Theory

Goldberg, J. (2017). The evolution of market needs, Trends in Leadership and Leadership Development, 20(1), 1-6.

Great expectations. (2016). Human Resource Management International Digest, 24(2), 32-35. Retrieved from http://ezproxy.bellevue.edu:80/login?url=https://search-proquestcom.ezproxy.bellevue.edu/docview/1765294985?accountid=28125

Haier, R. J.,Jung, R. E., Yeo, R.A., Head, K., Alkire, M. T. (2005). The neuroanatomy of general intelligence: Sex matters. NeuroImage. 25(1), 320-7.

Hershatter, A., \& Epstein, M. (June 2010). Millennials and the world of work: An organization and management perspective. Journal of Business and Psychology, 25(2), 211-223.

Howe, N., \& Strauss, W. (2000). Millennials rising: The next great generation. New York, NY: Vintage Books.

Kilburg, R. R., \& Donohue, M. D. (2011). Toward a "grand unifying theory" of leadership: Implications for consulting psychology. Consulting Psychology Journal: Practice and Research, 63(1), 6-25.

Mandell, B. and Pherwani, S. (2003), Relationship between emotional intelligence and transformational leadership styles: a gender comparison, Journal of Business and Psychology, 17(3), 387-404

Meisenberg, G. (Sept 2017). Sex differences in intelligence: Developmental origin yes, Jensen effect no. The mankind quarterly, 58(1), 101-108.

Ng, E. S.W., Schweitzer, L., \& Lyons, S.T. (June 2010). New generations, great expectations: A Field Study of the Millennial Generation. Journal of Business and Psychology, 25(2), 281-292.

Parry, K. W. (1998). Grounded theory and social process: A new direction for leadership research. Leadership Quarterly, 9(1), 85.

Rosener, J.B. (1990). Ways women lead, Harvard Business Review, 68, 119-125.

Schein, V.E. (1973). The relationship between sex roles stereotypes and requisite management characteristics, Journal of Applied Psychology, 57(2), 95-100.

Schein, V.E. (1975), Relationship between sex role stereotypes and requisite management characteristics among female managers, Journal of Applied Psychology, 60(3), 340-344. 


\section{MILLENNIALS’ VIEWS OF LEADERS}

Schein, V.E., Mueller, R., Lituchy, R., \& Liu, J. (1996). Think manager-think male: a global phenomenon, Journal of Organizational Behavior 17, 33-41.

Tulgan, B. (2009). Not everyone gets a trophy: How to manage generation y. New York: Jossey-Bass.

Twenge, J. M. (2010). A review of the empirical evidence on generational differences in work attitudes. Journal of Business and Psychology, 25, 201-210.

Twenge, J.M., \& Kasser, T. (2013). Generational changes in materialism and work centrality, 1976-2007 associations with temporal changes in societal insecurity and materialistic role modeling. Personality and Social Psychology Bulletin, 39, 883-897.

Vroom, V. H. \& Jago, A. G. (2007). The role of the situation in leadership. American Psychologist 62(1), 17-24.

Warner, J. (2014, March 7). Fact sheet: The women's leadership gap. Retrieved from https://cdn.americanprogress.org/wp-content/uploads/2014/03/WomenLeadership.pdf 